\title{
Gregus-Type Common Fixed Point Theorems for Tangential Multivalued Mappings of Integral Type in Metric Spaces
}

\author{
W. Sintunavarat and P. Kumam \\ Department of Mathematics, Faculty of Science, King Mongkut's University of Technology Thonburi \\ (KMUTT), Bangmod, Thrungkru, Bangkok 10140, Thailand \\ Correspondence should be addressed to P. Kumam, poom.kum@kmutt.ac.th
}

Received 28 November 2010; Accepted 11 February 2011

Academic Editor: Frank Werner

Copyright (C) 2011 W. Sintunavarat and P. Kumam. This is an open access article distributed under the Creative Commons Attribution License, which permits unrestricted use, distribution, and reproduction in any medium, provided the original work is properly cited.

\begin{abstract}
The concept of tangential for single-valued mappings is extended to multivalued mappings and used to prove the existence of a common fixed point theorem of Gregus type for four mappings satisfying a strict general contractive condition of integral type. Consequently, several known fixed point results generalized and improved the corresponding recent result of Pathak and Shahzad (2009) and many authors.
\end{abstract}

\section{Introduction}

The first important result on fixed points for contractive-type mappings was the well-known Banach contraction principle, published for the first time in 1922 in [1] (see also [2]). Banach contraction principle has been extended in many different directions, see [3-5], and so forth. Many authors in [3,5-12] established fixed point theorems involving more general contractive conditions. In 1969, Nadler [13] combines the ideas of set-valued mapping and Lipschitz mapping and prove some fixed point theorems about multivalued contraction mappings. Afterward, the study of fixed points for multivalued contractions using the Hausdorff metric was initiated by Markin [14]. Later, an interesting and rich fixed point theory for such maps was developed (see [15-18]). The theory of multivalued maps has applications in optimization problems, control theory, differential equations, and economics.

Sessa [19] introduced the concept of weakly commuting maps. Jungck [20] defined the notion of compatible maps in order to generalize the concept of weak commutativity and showed that weakly commuting mappings are compatible but the converse is not true. 
This concept was further improved by Jungck and Rhoades [21] with the notion of weakly compatible mappings. In 2002, Aamri and Moutawakil [22] defined property (E.A). This concept was frequently used to prove existence theorems in common fixed point theory. Three years later, Liu et al. [23] introduced common property (E.A). The class of (E.A) maps contains the class of noncompatible maps. Branciari [3] studied contractive conditions of integral type, giving an integral version of the Banach contraction principle, that could be extended to more general contractive conditions. Recently, Pathak and Shahzad [24] introduced the new concept of weak tangent point and tangential property for single-valued mappings and established common fixed point theorems. Very recently, Vetro [25] obtained an interesting theorem for mappings satisfying a contractive condition of integral type which is a generalization of Branciari [3, Theorem 2].

The aim of this paper is to define a tangential property for multivalued mappings which generalize the concept of tangential property for single-valued mappings of Pathak and Shahzad [24] and prove a common fixed point theorem of Gregus type for four mappings satisfying a strict general contractive condition of integral type.

\section{Preliminary}

Throughout this paper, $(X, d)$ denotes a metric space. We denote by $\mathrm{CB}(X)$, the class of all nonempty bounded closed subsets of $X$. The Hausdorff metric induced by $d$ on $\mathrm{CB}(X)$ is given by

$$
H(A, B)=\max \left\{\sup _{a \in A} d(a, B), \sup _{b \in B} d(b, A)\right\},
$$

for every $A, B \in \mathrm{CB}(X)$, where $d(a, B)=d(B, a)=\inf \{d(a, b): b \in B\}$ is the distance from $a$ to $B \subseteq X$. Let $f: X \rightarrow X$ and $T: X \rightarrow \mathrm{CB}(X)$. A point $x \in X$ is a fixed point of $f$ (resp. T) if $f x=x$ (resp. $x \in T x$ ). The set of all fixed points of $f$ (resp. $T$ ) is denoted by $F(f)$ (resp. $F(T)$ ). A point $x \in X$ is a coincidence point of $f$ and $T$ if $f x \in T x$. The set of all coincidence points of $f$ and $T$ is denoted by $C(f, T)$. A point $x \in X$ is a common fixed point of $f$ and $T$ if $x=f x \in T x$. The set of all common fixed points of $f$ and $T$ is denoted by $F(f, T)$.

Definition 2.1. The maps $f: X \rightarrow X$ and $g: X \rightarrow X$ are said to be commuting if $f g x=g f x$, for all $x \in X$.

Definition 2.2 (see [19]). The maps $f: X \rightarrow X$ and $g: X \rightarrow X$ are said to be weakly commuting if $d(f g x, g f x) \leq d(f x, g x)$, for all $x \in X$.

Definition 2.3 (see [20]). The maps $f: X \rightarrow X$ and $g: X \rightarrow X$ are said to be compatible if $\lim _{n \rightarrow \infty} d\left(f g x_{n}, g f x_{n}\right)=0$ whenever $\left\{x_{n}\right\}$ is a sequence in $X$ such that $\lim _{n \rightarrow \infty} f x_{n}=$ $\lim _{n \rightarrow \infty} g x_{n}=z$, for some $z \in X$.

Definition 2.4 (see [26]). The maps $f: X \rightarrow X$ and $g: X \rightarrow X$ are said to be weakly compatible $f g x=g f x$, for all $x \in C(f, g)$. 
Definition 2.5 (see [22]). Let $f: X \rightarrow X$ and $g: X \rightarrow X$. The pair $(f, g)$ satisfies property (E.A) if there exist the sequence $\left\{x_{n}\right\}$ in $X$ such that

$$
\lim _{n \rightarrow \infty} f x_{n}=\lim _{n \rightarrow \infty} g x_{n}=z \in X
$$

See example of property (E.A) in Kamran [27, 28] and Sintunavarat and Kumam [11].

Definition 2.6 (see [23]). Let $f, g, A, B: X \rightarrow X$. The pair $(f, g)$ and $(A, B)$ satisfy a common property (E.A) if there exist sequences $\left\{x_{n}\right\}$ and $\left\{y_{n}\right\}$ in $X$ such that

$$
\lim _{n \rightarrow \infty} f x_{n}=\lim _{n \rightarrow \infty} g x_{n}=\lim _{n \rightarrow \infty} A y_{n}=\lim _{n \rightarrow \infty} B y_{n}=z \in X
$$

Remark 2.7. If $A=f, B=g$, and $\left\{x_{n}\right\}=\left\{y_{n}\right\}$ in (2.3), then we get the definition of property (E.A).

Definition 2.8 (see [24]). Let $f, g: X \rightarrow X$. A point $z \in X$ is said to be a weak tangent point to $(f, g)$ if there exist sequences $\left\{x_{n}\right\}$ and $\left\{y_{n}\right\}$ in $X$ such that

$$
\lim _{n \rightarrow \infty} f x_{n}=\lim _{n \rightarrow \infty} g y_{n}=z \in X
$$

Remark 2.9. If $\left\{x_{n}\right\}=\left\{y_{n}\right\}$ in (2.4), we get the definition of property (E.A).

Definition 2.10 (see [24]). Let $f, g, A, B: X \rightarrow X$. The pair $(f, g)$ is called tangential with respect to the pair $(A, B)$ if there exist sequences $\left\{x_{n}\right\}$ and $\left\{y_{n}\right\}$ in $X$ such that

$$
\lim _{n \rightarrow \infty} f x_{n}=\lim _{n \rightarrow \infty} g y_{n}=\lim _{n \rightarrow \infty} A x_{n}=\lim _{n \rightarrow \infty} B y_{n}=z \in X
$$

\section{Main Results}

In this section, we first introduce the notion of tangential property for two single-valued and two multivalued mappings. Throughout this section, $\mathbb{R}_{+}$denotes the set of nonnegative real numbers.

Definition 3.1. Let $f, g: X \rightarrow X$ and $A, B: X \rightarrow \mathrm{CB}(X)$. The pair $(f, g)$ is called tangential with respect to the pair $(A, B)$ if

$$
\lim _{n \rightarrow \infty} A x_{n}=\lim _{n \rightarrow \infty} B y_{n}=D \in \mathrm{CB}(X),
$$

whenever sequences $\left\{x_{n}\right\}$ and $\left\{y_{n}\right\}$ in $X$ such that

$$
\lim _{n \rightarrow \infty} f x_{n}=\lim _{n \rightarrow \infty} g y_{n}=z \in D,
$$

for some $z \in X$. 
Example 3.2. Let $\left(\mathbb{R}_{+}, d\right)$ be a metric space with usual metric $d$. Let $f, g: \mathbb{R}_{+} \rightarrow \mathbb{R}_{+}$and $A, B: \mathbb{R}_{+} \rightarrow \mathrm{CB}\left(\mathbb{R}_{+}\right)$be mappings defined by $f x=x+1, g x=x+2, A x=\left\{x^{2} / 2+1\right\}$, and $B x=\left\{x^{2}+2\right\}$, for all $x \in \mathbb{R}_{+}$. Clearly, there exists two sequences $\left\{x_{n}=2+1 / n\right\}$ and $\left\{y_{n}=1+1 / n\right\}$ such that

$$
\lim _{n \rightarrow \infty} A x_{n}=\lim _{n \rightarrow \infty} B y_{n}=\{3\} \in \mathrm{CB}\left(\mathbb{R}_{+}\right)
$$

whenever

$$
\lim _{n \rightarrow \infty} f x_{n}=\lim _{n \rightarrow \infty} g y_{n}=3 \in \mathbb{R}_{+} .
$$

So, the pair $(f, g)$ is tangential with respect to the pair $(A, B)$.

Definition 3.3. Let $f: X \rightarrow X$ and $A: X \rightarrow \mathrm{CB}(X)$. The mapping $f$ is called tangential with respect to the mapping $A$ if

$$
\lim _{n \rightarrow \infty} A x_{n}=\lim _{n \rightarrow \infty} A y_{n}=D \in \mathrm{CB}(X),
$$

whenever sequences $\left\{x_{n}\right\}$ and $\left\{y_{n}\right\}$ in $X$ such that

$$
\lim _{n \rightarrow \infty} f x_{n}=\lim _{n \rightarrow \infty} f y_{n}=z \in D,
$$

for some $z \in X$.

Example 3.4. Let $\left(\mathbb{R}_{+}, d\right)$ be a metric space with usual metric $d$. Let $f: \mathbb{R}_{+} \rightarrow \mathbb{R}_{+}$and $A: \mathbb{R}_{+} \rightarrow$ $\mathrm{CB}\left(\mathbb{R}_{+}\right)$be mappings defined by

$$
f x=x+1, \quad A x=\left\{x^{2}+1\right\}
$$

Clearly, there exist two sequences $\left\{x_{n}=1+1 / n\right\}$ and $\left\{y_{n}=1-1 / n\right\}$ such that

$$
\lim _{n \rightarrow \infty} A x_{n}=\lim _{n \rightarrow \infty} A y_{n}=\{2\} \in \mathrm{CB}\left(\mathbb{R}_{+}\right)
$$

whenever

$$
\lim _{n \rightarrow \infty} f x_{n}=\lim _{n \rightarrow \infty} f y_{n}=2 \in \mathbb{R}_{+} .
$$

So, the mapping $f$ is tangential with respect to the mapping $A$.

Now, we state and prove our main result. 
Theorem 3.5. Let $f, g: X \rightarrow X$ and $A, B: X \rightarrow C B(X)$ satisfy

$$
\begin{aligned}
&\left(1+\alpha \int_{0}^{d(f x, g y)} \psi(t) d t\right) \int_{0}^{H(A x, B y)} \psi(t) d t \\
&<\alpha\left(\int_{0}^{d(A x, f x)} \psi(t) d t \int_{0}^{d(B y, g y)} \psi(t) d t+\int_{0}^{d(A x, g y)} \psi(t) d t \int_{0}^{d(f x, B y)} \psi(t) d t\right) \\
&+a \int_{0}^{d(f x, g y)} \psi(t) d t+(1-a) \max \left\{\int_{0}^{d(A x, f x)} \psi(t) d t, \int_{0}^{d(B y, g y)} \psi(t) d t,\right. \\
&\left(\int_{0}^{d(A x, f x)} \psi(t) d t\right)^{1 / 2}\left(\int_{0}^{d(A x, g y)} \psi(t) d t\right)^{1 / 2}, \\
&\left.\left(\int_{0}^{d(f x, B y)} \psi(t) d t\right)^{1 / 2}\left(\int_{0}^{d(A x, g y)} \psi(t) d t\right)^{1 / 2}\right\},
\end{aligned}
$$

for all $x, y \in X$ for which the right-hand side of (3.10) is positive, where $0<a<1, \alpha \geq 0$ and $\psi: \mathbb{R}_{+} \rightarrow \mathbb{R}_{+}$is a Lebesgue integrable mapping which is a summable nonnegative and such that

$$
\int_{0}^{\epsilon} \psi(t) d t>0
$$

for each $\epsilon>0$. If the following conditions (a)-(d) hold:

(a) there exists a point $z \in f(X) \cap g(X)$ which is a weak tangent point to $(f, g)$,

(b) $(f, g)$ is tangential with respect to $(A, B)$,

(c) $f f a=f a, g g b=g b$, and $A f a=B g b$ for $a \in C(f, A)$ and $b \in C(g, B)$,

(d) the pairs $(f, A)$ and $(g, B)$ are weakly compatible.

Then, $f, g, A$, and B have a common fixed point in $X$.

Proof. Since $z \in f(X) \cap g(X), z=f u=g v$ for some $u, v \in X$. It follows from a point $z$ which is a weak tangent point to $(f, g)$ that there exist sequences $\left\{x_{n}\right\}$ and $\left\{y_{n}\right\}$ in $X$ such that

$$
\lim _{n \rightarrow \infty} f x_{n}=\lim _{n \rightarrow \infty} g y_{n}=z
$$


Because the pair $(f, g)$ is tangential with respect to the pair $(A, B)$, we get

$$
\lim _{n \rightarrow \infty} A x_{n}=\lim _{n \rightarrow \infty} B y_{n}=D
$$

for some $D \in \mathrm{CB}(X)$. Since $z=f u=g v$ and (3.12) and (3.13) are true, we have

$$
z=f u=g v=\lim _{n \rightarrow \infty} f x_{n}=\lim _{n \rightarrow \infty} g y_{n} \in \lim _{n \rightarrow \infty} A x_{n}=\lim _{n \rightarrow \infty} B y_{n}=D
$$

We claim that $z \in B v$. If not, then condition (3.10) implies

$$
\begin{aligned}
&\left(1+\alpha \int_{0}^{d\left(f x_{n}, g v\right)} \psi(t) d t\right) \int_{0}^{H\left(A x_{n}, B v\right)} \psi(t) d t \\
&<\alpha\left(\int_{0}^{d\left(A x_{n}, f x_{n}\right)} \psi(t) d t \int_{0}^{d(B v, g v)} \psi(t) d t+\int_{0}^{d\left(A x_{n}, g v\right)} \psi(t) d t \int_{0}^{d\left(f x_{n}, B v\right)} \psi(t) d t\right) \\
&+a \int_{0}^{d\left(f x_{n}, g v\right)} \psi(t) d t+(1-a) \max \left\{\int_{0}^{d\left(A x_{n}, f x_{n}\right)} \psi(t) d t, \int_{0}^{d(B v, g v)} \psi(t) d t,\right. \\
&\left(\int_{0}^{d\left(A x_{n}, f x_{n}\right)} \psi(t) d t\right)^{1 / 2}\left(\int_{0}^{d\left(A x_{n}, g v\right)} \psi(t) d t\right)^{1 / 2}, \\
&\left.\left(\int_{0}^{d\left(f x_{n}, B v\right)} \psi(t) d t\right)^{1 / 2}\left(\int_{0}^{d\left(A x_{n}, g v\right)} \psi(t) d t\right)^{1 / 2}\right\} .
\end{aligned}
$$

Letting $n \rightarrow \infty$, we get

$$
\int_{0}^{H(D, B v)} \psi(t) d t \leq(1-a) \int_{0}^{d(B v, z)} \psi(t) d t .
$$

Since

$$
\begin{aligned}
\int_{0}^{d(z, B v)} \psi(t) d t & <\int_{0}^{H(D, B v)} \psi(t) d t \\
& \leq(1-a) \int_{0}^{d(B v, z)} \psi(t) d t \\
& <\int_{0}^{d(z, B v)} \psi(t) d t
\end{aligned}
$$

which is a contradiction, then $z \in B v$. 
Again, we claim that $z \in A u$. If not, then condition (3.10) implies

$$
\begin{aligned}
&\left(1+\alpha \int_{0}^{d\left(f u, g y_{n}\right)} \psi(t) d t\right) \int_{0}^{H\left(A u, B y_{n}\right)} \psi(t) d t \\
&<\alpha\left(\int_{0}^{d(A u, f u)} \psi(t) d t \int_{0}^{d\left(B y_{n}, g y_{n}\right)} \psi(t) d t+\int_{0}^{d\left(A u, g y_{n}\right)} \psi(t) d t \int_{0}^{d\left(f u, B y_{n}\right)} \psi(t) d t\right) \\
&+a \int_{0}^{d\left(f u, g y_{n}\right)} \psi(t) d t+(1-a) \max \left\{\int_{0}^{d(A u, f u)} \psi(t) d t, \int_{0}^{d\left(B y_{n}, g y_{n}\right)} \psi(t) d t,\right. \\
&\left(\int_{0}^{d(A u, f u)} \psi(t) d t\right)^{1 / 2}\left(\int_{0}^{d\left(A u, g y_{n}\right)} \psi(t) d t\right)^{1 / 2}, \\
&\left.\left(\int_{0}^{d\left(f u, B y_{n}\right)} \psi(t) d t\right)^{1 / 2}\left(\int_{0}^{d\left(A u, g y_{n}\right)} \psi(t) d t\right)^{1 / 2}\right\} .
\end{aligned}
$$

Letting $n \rightarrow \infty$, we get

$$
\int_{0}^{H(A u, D)} \psi(t) d t \leq(1-a) \int_{0}^{d(A u, z)} \psi(t) d t .
$$

Since

$$
\begin{aligned}
\int_{0}^{d(z, A u)} \psi(t) d t & <\int_{0}^{H(A u, D)} \psi(t) d t \\
& \leq(1-a) \int_{0}^{d(A u, z)} \psi(t) d t \\
& <\int_{0}^{d(z, A u)} \psi(t) d t
\end{aligned}
$$

which is a contradiction, then $z \in A u$.

Now, we conclude $z=g v \in B v$ and $z=f u \in A u$. It follows from $v \in C(g, B)$, $u \in C(f, A)$ that $g g v=g v, f f u=f u$, and $A f u=B g v$. Hence, $g z=z, f z=z$ and $A z=B z$.

Since the pair $(g, B)$ is weakly compatible, $g B v=B g v$. Thus $g z \in g B v=B g v=B z$. Similarly, we can prove that $f z \in A z$. Consequently, $z=f z=g z \in A z=B z$. Therefore the maps $f, g, A$, and $B$ have a common fixed point.

If $\alpha=0$ in Theorem 3.5, we get the following corollary. 
Corollary 3.6. Let $f, g: X \rightarrow X$ and $A, B: X \rightarrow C B(X)$ satisfy

$$
\begin{aligned}
\int_{0}^{H(A x, B y)} \psi(t) d t< & a \int_{0}^{d(f x, g y)} \psi(t) d t \\
+(1-a) \max \{ & \int_{0}^{d(A x, f x)} \psi(t) d t, \int_{0}^{d(B y, g y)} \psi(t) d t, \\
& \left(\int_{0}^{d(A x, f x)} \psi(t) d t\right)^{1 / 2}\left(\int_{0}^{d(A x, g y)} \psi(t) d t\right)^{1 / 2}, \\
& \left.\left(\int_{0}^{d(f x, B y)} \psi(t) d t\right)^{1 / 2}\left(\int_{0}^{d(A x, g y)} \psi(t) d t\right)^{1 / 2}\right\},
\end{aligned}
$$

for all $x, y \in X$ for which the right-hand side of (3.21) is positive, where $0<a<1$ and $\psi: \mathbb{R}_{+} \rightarrow \mathbb{R}_{+}$ is a Lebesgue integrable mapping which is a summable nonnegative and such that

$$
\int_{0}^{\epsilon} \psi(t) d t>0
$$

for each $\epsilon>0$. If the following conditions (a)-(d) hold:

(a) there exists a point $z \in f(X) \cap g(X)$ which is a weak tangent point to $(f, g)$,

(b) $(f, g)$ is tangential with respect to $(A, B)$,

(c) $f f a=f a, g g b=g b$ and $A f a=B g b$ for $a \in C(f, A)$ and $b \in C(g, B)$,

(d) the pairs $(f, A)$ and $(g, B)$ are weakly compatible.

Then, $f, g, A$, and B have a common fixed point in $X$.

If $\alpha=0, g=f$, and $B=A$ in Theorem 3.5, we get the following corollary.

Corollary 3.7. Let $f: X \rightarrow X$ and $A: X \rightarrow C B(X)$ satisfy

$$
\begin{aligned}
\int_{0}^{H(A x, A y)} \psi(t) d t< & a \int_{0}^{d(f x, f y)} \psi(t) d t \\
+(1-a) \max \{ & \int_{0}^{d(A x, f x)} \psi(t) d t, \int_{0}^{d(A y, f y)} \psi(t) d t \\
& \left(\int_{0}^{d(A x, f x)} \psi(t) d t\right)^{1 / 2}\left(\int_{0}^{d(A x, f y)} \psi(t) d t\right)^{1 / 2}, \\
& \left.\left(\int_{0}^{d(f x, A y)} \psi(t) d t\right)^{1 / 2}\left(\int_{0}^{d(A x, f y)} \psi(t) d t\right)^{1 / 2}\right\},
\end{aligned}
$$


for all $x, y \in X$ for which the right-hand side of (3.23) is positive, where $0<a<1$ and $\psi: \mathbb{R}_{+} \rightarrow \mathbb{R}_{+}$ is a Lebesgue integrable mapping which is a summable nonnegative and such that

$$
\int_{0}^{\epsilon} \psi(t) d t>0
$$

for each $\epsilon>0$. If the following conditions (a)-(d) hold:

(a) there exists sequence $\left\{x_{n}\right\}$ in $X$ such that $\lim _{n \rightarrow \infty} f x_{n} \in X$,

(b) $f$ is tangential with respect to $A$,

(c) $f f a=$ fa for $a \in C(f, A)$,

(d) the pair $(f, A)$ is weakly compatible.

Then, $f$ and A have a common fixed point in $X$.

If $\psi(t)=1$ in Theorem 3.5, we get the following corollary.

Corollary 3.8. Let $f, g: X \rightarrow X$ and $A, B: X \rightarrow C B(X)$ satisfy

$$
\begin{gathered}
(1+\alpha d(f x, g y)) H(A x, B y) \\
<\alpha(d(A x, f x) d(B y, g y)+d(A x, g y) d(f x, B y))+a d(f x, g y) \\
+(1-a) \max \left\{d(A x, f x), d(B y, g y),(d(A x, f x))^{1 / 2}(d(A x, g y))^{1 / 2},\right. \\
\left.(d(f x, B y))^{1 / 2}(d(A x, g y))^{1 / 2}\right\}
\end{gathered}
$$

for all $x, y \in X$ for which the right-hand side of (3.25) is positive, where $0<a<1$ and $\alpha \geq 0$. If the following conditions (a) $-(d)$ holds:

(a) there exists a point $z \in f(X) \cap g(X)$ which is a weak tangent point to $(f, g)$,

(b) $(f, g)$ is tangential with respect to $(A, B)$,

(c) $f f a=f a, g g b=g b$ and $A f a=B g b$ for $a \in C(f, A)$ and $b \in C(g, B)$,

(d) the pairs $(f, A)$ and $(g, B)$ are weakly compatible.

Then, $f, g, A$, and B have a common fixed point in X.

If $\psi(t)=1$ and $\alpha=0$ in Theorem 3.5, we get the following corollary.

Corollary 3.9. Let $f, g: X \rightarrow X$ and $A, B: X \rightarrow C B(X)$ satisfy

$$
\begin{aligned}
H(A x, B y)< & a d(f x, g y) \\
+ & (1-a) \max \left\{d(A x, f x), d(B y, g y),(d(A x, f x))^{1 / 2}(d(A x, g y))^{1 / 2},\right. \\
& \left.(d(f x, B y))^{1 / 2}(d(A x, g y))^{1 / 2}\right\},
\end{aligned}
$$


for all $x, y \in X$ for which the right-hand side of (3.26) is positive, where $0<a<1$. If the following conditions (a)-(d) hold:

(a) there exists a point $z \in f(X) \cap g(X)$ which is a weak tangent point to $(f, g)$,

(b) $(f, g)$ is tangential with respect to $(A, B)$,

(c) $f f a=f a, g g b=g b$ and $A f a=B g b$ for $a \in C(f, A)$ and $b \in C(g, B)$,

(d) the pairs $(f, A)$ and $(g, B)$ are weakly compatible.

Then, $f, g, A$, and B have a common fixed point in $X$.

If $\psi(t)=1, \alpha=0, g=f$ and $B=A$ in Theorem 3.5, we get the following corollary.

Corollary 3.10. Let $f: X \rightarrow X$ and $A: X \rightarrow C B(X)$ satisfy

$$
\begin{gathered}
H(A x, A y)<a d(f x, f y) \\
+(1-a) \max \left\{d(A x, f x), d(A y, f y),(d(A x, f x))^{1 / 2}(d(A x, f y))^{1 / 2},\right. \\
\left.(d(f x, A y))^{1 / 2}(d(A x, f y))^{1 / 2}\right\}
\end{gathered}
$$

for all $x, y \in X$ for which the right-hand side of (3.27) is positive, where $0<a<1$. If the following conditions (a)-(d) holds:

(a) there exists sequence $\left\{x_{n}\right\}$ in $X$ such that $\lim _{n \rightarrow \infty} f x_{n} \in X$,

(b) $f$ is tangential with respect to $A$,

(c) $f f a=$ fa for $a \in C(f, A)$,

(d) the pairs $(f, A)$ is weakly compatible.

Then, $f$ and $A$ have a common fixed point in $X$.

\section{Acknowledgments}

W. Sintunavarat would like to thank the Research Professional Development Project under the Science Achievement Scholarship of Thailand (SAST) and the Faculty of Science, KMUTT for financial support during the preparation of this manuscript for Ph.D. Program at KMUTT. Moreover, the authors also would like to thank the National Research University Project of Thailand's Office of the Higher Education Commission for financial support (under the CSEC project no. 54000267). Finally, the authors would like to thank Professor Frank Werner for your help and encouragement. Special thanking are also due to the reviewers, who have made a number of valuable comments and suggestions which have improved the manuscript greatly. 


\section{References}

[1] S. Banach, "Sur les opérations dans les ensembles abstraits et leurs applications aux équations intérales," Fundamenta Mathematicae, vol. 3, pp. 133-181, 1922.

[2] R. Caccioppoli, "Un teorema generale sull esistenza di elementi uniti in una trasformazione funzionale," Rendiconti Academia dei Lincei, vol. 11, pp. 794-799, 1930 (Italian).

[3] A. Branciari, "A fixed point theorem for mappings satisfying a general contractive condition of integral type," International Journal of Mathematics and Mathematical Sciences, vol. 29, no. 9, pp. 531536, 2002.

[4] N. Shahzad, "Invariant approximations and R-subweakly commuting maps," Journal of Mathematical Analysis and Applications, vol. 257, no. 1, pp. 39-45, 2001.

[5] P. Vijayaraju, B. E. Rhoades, and R. Mohanraj, "A fixed point theorem for a pair of maps satisfying a general contractive condition of integral type," International Journal of Mathematics and Mathematical Sciences, no. 15, pp. 2359-2364, 2005.

[6] R. P. Agarwal, D. O'Regan, and N. Shahzad, "Fixed point theory for generalized contractive maps of Meir-Keeler type," Mathematische Nachrichten, vol. 276, pp. 3-22, 2004.

[7] I. Altun, D. Türkoğlu, and B. E. Rhoades, "Fixed points of weakly compatible maps satisfying a general contractive condition of integral type," Fixed Point Theory and Applications, vol. 2007, Article ID 17301, 9 pages, 2007.

[8] I. Altun and D. Turkoglu, "Some fixed point theorems for weakly compatible multivalued mappings satisfying some general contractive conditions of integral type," Bulletin of Iranian Mathematical Society, vol. 36, no. 1, pp. 55-67, 2010.

[9] A. Azam and M. Arshad, "Common fixed points of generalized contractive maps in cone metric spaces," Bulletin of Iranian Mathematical Society, vol. 35, no. 2, pp. 255-264, 2009.

[10] A. Razani and R. Moradi, "Common fixed point theorems of integral type in modular spaces," Bulletin of Iranian Mathematical Society, vol. 35, no. 2, pp. 11-24, 2009.

[11] W. Sintunavarat and P. Kumam, "Coincidence and common fixed points for hybrid strict contractions without the weakly commuting condition," Applied Mathematics Letters, vol. 22, no. 12, pp. 1877-1881, 2009.

[12] W. Sintunavarat and P. Kumam, "Weak condition for generalized multi-valued $(f, \alpha, \beta)$-weak contraction mappings," Applied Mathematics Letters, vol. 24, no. 4, pp. 460-465, 2011.

[13] S. B. Nadler Jr., "Multi-valued contraction mappings," Pacific Journal of Mathematics, vol. 30, pp. 475488, 1969.

[14] J. T. Markin, "Continuous dependence of fixed point sets," Proceedings of the American Mathematical Society, vol. 38, pp. 545-547, 1973.

[15] J.-P. Aubin and J. Siegel, "Fixed points and stationary points of dissipative multivalued maps," Proceedings of the American Mathematical Society, vol. 78, no. 3, pp. 391-398, 1980.

[16] H. Covitz and S. B. Nadler Jr., "Multi-valued contraction mappings in generalized metric spaces," Israel Journal of Mathematics, vol. 8, pp. 5-11, 1970.

[17] W. Sintunavarat, P. Kumam, and P. Patthanangkoor, "Common random fixed points for multivalued random operators without $S$ - and $T$-weakly commuting random," Random Operators and Stochastic Equations, vol. 17, no. 4, pp. 381-388, 2009.

[18] T. X. Wang, "Fixed-point theorems and fixed-point stability for multivalued mappings on metric spaces," Jounal of Nanjing University, Mathematical Biquarterly, vol. 6, no. 1, pp. 16-23, 1989.

[19] S. Sessa, "On a weak commutativity condition of mappings in fixed point considerations," Institut Mathématique. Publications. Nouvelle Série, vol. 32, no. 46, pp. 149-153, 1982.

[20] G. Jungck, "Compatible mappings and common fixed points," International Journal of Mathematics and Mathematical Sciences, vol. 9, no. 4, pp. 771-779, 1986.

[21] G. Jungck and B. E. Rhoades, "Fixed point theorems for occasionally weakly compatible mappings," Fixed Point Theory, vol. 7, no. 2, pp. 286-296, 2006.

[22] M. Aamri and D. El Moutawakil, "Some new common fixed point theorems under strict contractive conditions," Journal of Mathematical Analysis and Applications, vol. 270, no. 1, pp. 181-188, 2002.

[23] Y. Liu, J. Wu, and Z. Li, "Common fixed points of single-valued and multivalued maps," International Journal of Mathematics and Mathematical Sciences, no. 19, pp. 3045-3055, 2005.

[24] H. K. Pathak and N. Shahzad, "Gregus type fixed point results for tangential mappings satisfying contractive conditions of integral type," Bulletin of the Belgian Mathematical Society. Simon Stevin, vol. 16, no. 2, pp. 277-288, 2009. 
[25] C. Vetro, "On Branciari's theorem for weakly compatible mappings," Applied Mathematics Letters, vol. 23, no. 6, pp. 700-705, 2010.

[26] G. Jungck, "Common fixed points for noncontinuous nonself maps on nonmetric spaces," Far East Journal of Mathematical Sciences, vol. 4, no. 2, pp. 199-215, 1996.

[27] T. Kamran, "Coincidence and fixed points for hybrid strict contractions," Journal of Mathematical Analysis and Applications, vol. 299, no. 1, pp. 235-241, 2004.

[28] T. Kamran, "Multivalued $f$-weakly Picard mappings," Nonlinear Analysis: Theory, Methods $\mathcal{E}$ Applications, vol. 67, no. 7, pp. 2289-2296, 2007. 


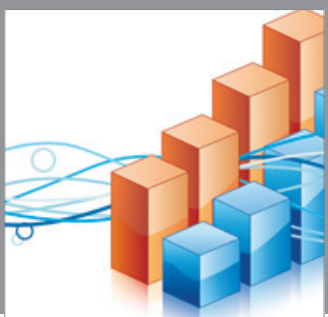

Advances in

Operations Research

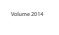

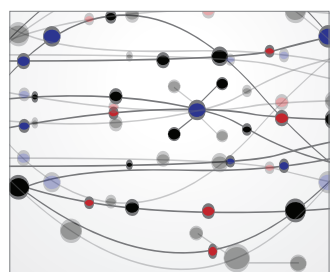

\section{The Scientific} World Journal
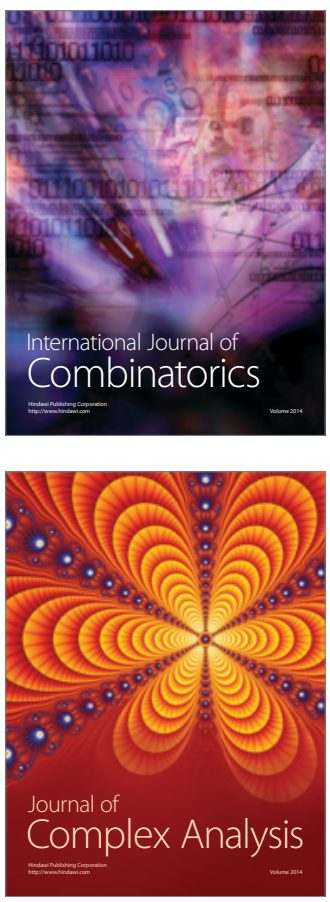

International Journal of

Mathematics and

Mathematical

Sciences
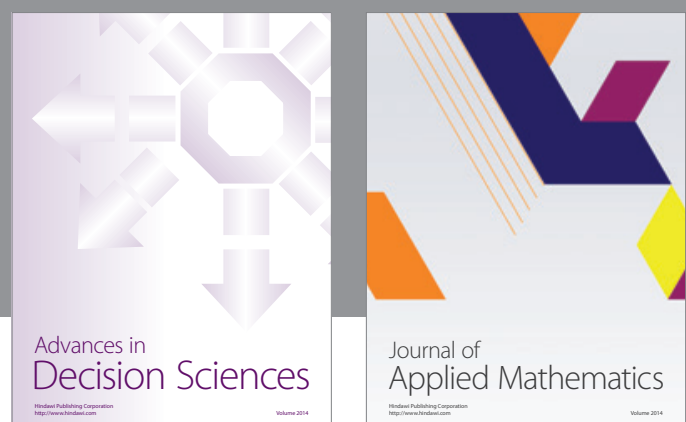

Journal of

Applied Mathematics
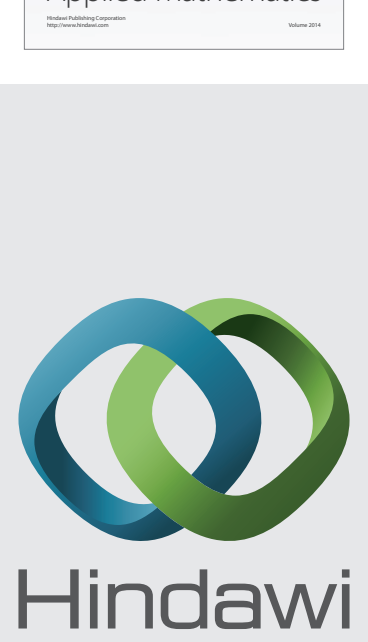

Submit your manuscripts at http://www.hindawi.com
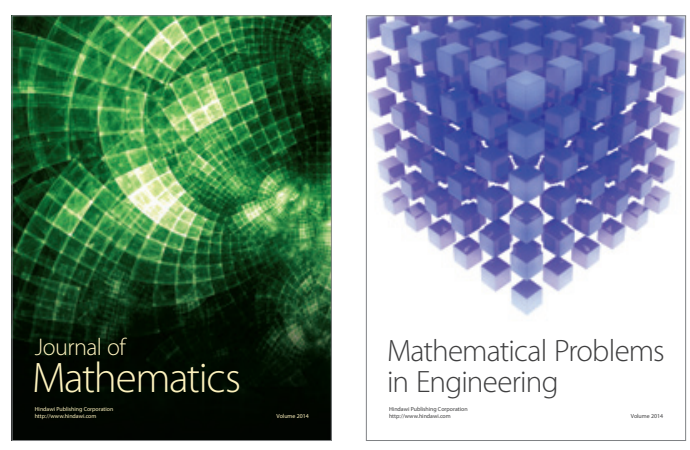

Mathematical Problems in Engineering
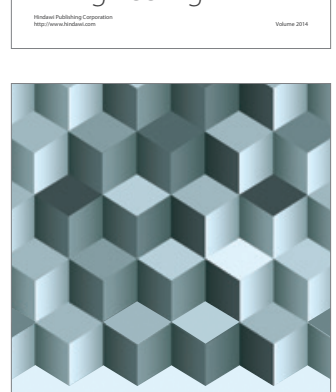

Journal of

Function Spaces
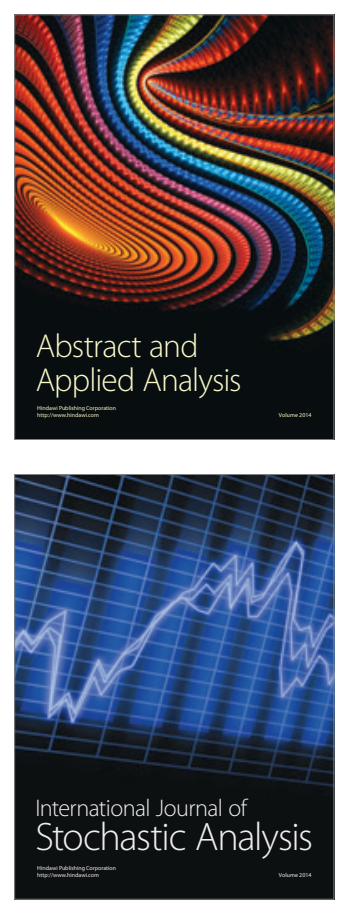

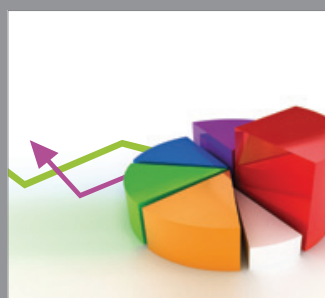

ournal of

Probability and Statistics

Promensencen
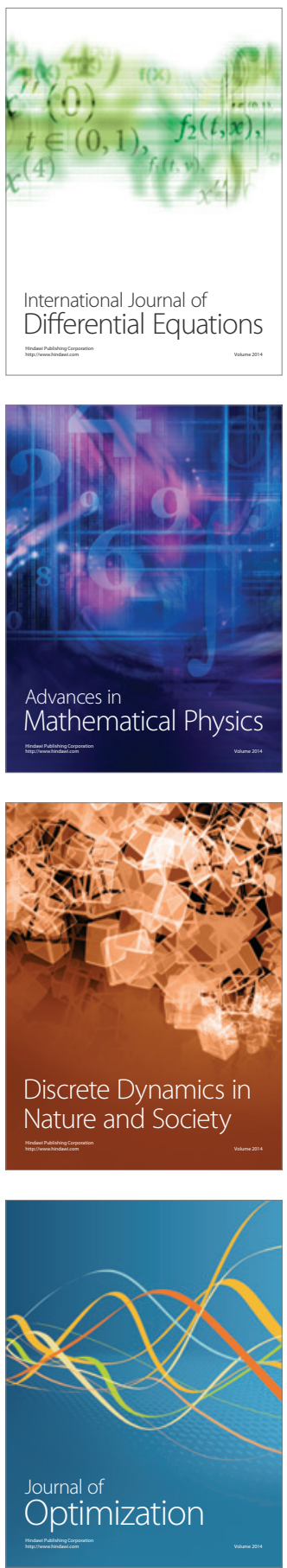